\title{
PUBLICAÇÕES SOBRE ARBORIZAÇÃO URBANA NA REGIÃO NORDESTE, BRASIL
}

\author{
PUBLICATIONS ON URBAN AFFORESTATION IN THE NORTHEAST REGION, \\ $B R A Z I L$
}

Joedla Rodrigues de Lima' ${ }^{1}$, Luiz Soares de Oliveira Filho²

\section{RESUMO}

Este trabalho realizou o levantamento das publicações sobre arborização urbana no Nordeste do Brasil, em periódicos nacionais, entre os anos de 2008 e 2017. Foram analisados 23 artigos publicados em 8 periódicos, sendo treze desenvolvidos no semiárido, três em área de transição e sete no litoral Nordestino. O estado que mais apresentou trabalhos foi a Paraíba, sendo a maioria desenvolvidos pela Universidade Federal de Campina Grande. A metodologia predominante foi o inventário, com identificação qualiquantitativa em ruas ou praças. A maioria dos trabalhos desenvolvidos constataram a predominância de espécies exóticas, sendo as espécies de maior ocorrência Azadirachta A. Juss (Nin indiano), seguido da Ficus benjamina $L$ (fícus). Nos trabalhos do litoral, verifica-se a utilização de árvores frutíferas, como Syzygium malaccense L Merr. \& L. M. Perry (Jambo) e Mangueira indica L (manga). Os trabalhos enfatizam a necessidade de planejamento da arborização urbana e dois artigos sugerem a realização de atividades de educação ambiental com a população.

Palavras-chave: Floresta Urbana; Plano de Arborização; Meio Ambiente.

\begin{abstract}
This paper carried out a survey of publications on urban afforestation in the Brazilian northeast, on national journals, between 2008 and 2017. Eight journals were found, totalizing 23 articles, 13 out of them were developed in the semiarid, 3 in a climate transition area, and 7 on the coast. The state and the institution which presented the largest amount of papers were Paraiba and the Federal University of Campina Grande. The predominant methodology was the inventory, with quali-quantitative identification on streets and squares. Most research concluded that exotic species are predominant, with the highest prevalence of Azadirachta indica and A. Juss (Indian Neem tree) followed by Ficus benjamina L (ficus). In coastal studies, it is possible to verify the use of Syzygium malaccense L Merr. \& L. M. Perry (mountain apple) and the Mangueira indica (mango tree). The studies highlighted the necessity of urban afforestation planning, two of them suggested the implementation of environmental education activities to be carried out with the population.
\end{abstract}

Keywords: Urban Forest; Afforestation Plan; Environment.

Recebido em 13.02.2020 e aceito em 15.07.2020

1 Engenheira Agrícola. Dra. Professora da Universidade Federal de Campina Grande. Patos/PB.

Email:joedla.rodrigues@professor.ufcg.edu.br

2 Engenheiro Florestal. Universidade Federal de Campina Grande. Patos/PB. Email: luizsoares846@gmail.com 


\section{INTRODUÇÃO}

O acesso e divulgação da informação, especificamente tratando das pesquisas na área de arborização adquire atualmente maior visibilidade, pelos benefícios ambientais e de bem estar que proporciona no ambiente urbano. Neste cenário, os periódicos científicos exercem papel fundamental, pois contribui na divulgação do estado da arte das pesquisas, permitindo que se construa o cenário regional sobre a arborização urbana e, ou, institucional, em relação ao teor das pesquisas, incluindo as contribuições metodológicas.

Em relação as publicações sobre arborização urbana, construir uma visão sinótica, indica qual a tendência das pesquisas, suas lacunas, suas contribuições, ao mesmo tempo que ressaltam a relevância do tema como elemento de equilíbrio ambiental e mitigação do efeito estufa. O crescimento da população urbana, geram impactos ao ambiente, tais como, a impermeabilização do solo, a poluição do ar e a supressão da vegetação, que causam desequilíbrio na natureza e nas interações Atmosfera-Terra (FEITOSA et al., 2011)

Inclusive, a atividade humana, baseada no uso intensivo dos recursos naturais está interferindo no microclima das cidades, gerando aumento de temperatura e alterando o ciclo hidrológico e, quanto mais uma cidade cresce desordenadamente, ocorrem mais alterações no ambiente, dificultando a vida dos munícipes (SPÓSITO, 2001).

Diante dos impactos negativos gerados pelo modelo de civilização que prepondera, conferências mundiais foram realizadas, a partir da década de 1970, com o objetivo de conciliar desenvolvimento e meio ambiente, discutindo-se uma proposta de desenvolvimento sustentável (HERCULANO, 1992). Após 38 anos da criação do termo e de incentivos para que se considere o âmbito da sustentabilidade ambiental nos projetos urbanos, o Nordeste brasileiro pouco tem avançado nesta conceituação de desenvolvimento.

Para minimizar os principais impactos no processo de arborização urbana, Carvalho; Nogueira e Lemos (2016), destacam a importância de haja planejamento e que este integre os poderes municipal, estadual, as concessionárias de energia, as telefônicas, sistemas de água e esgoto, a fim de minimizar os problemas que uma arborização mal conduzida pode acarretar.

Diante deste cenário de insustentabilidade ambiental, este trabalho levantou publicações sobre arborização urbana na área de agrárias, desenvolvidas na região Nordeste, num intervalo de dez anos, entre 2008 a 2017, com o objetivo de subsidiar gestores e pesquisadores nesta temática que está cada dia mais relevante para a qualidade de vida urbana.

Deste levantamento, inferiu-se qual a metodologia que prepondera nos artigos, qual o estado da arborização e quais as espécies que preponderam na região, onde se localizam as publicações e as instituições responsáveis. 


\section{MATERIAL E MÉTODOS}

A metodologia empregada consistiu em levantamento qualitativo e quantitativo de publicações acadêmicas brasileiras, no formato de artigos científicos cuja temática fosse "arborização urbana", disponibilizados no sistema "qualis capes".

O procedimento inicial constou na busca de artigos publicados em periódicos científicos disponibilizado no sistema de Consulta "Portal de Periódicos" da Coordenação de Aperfeiçoamento de pessoal de Nível Superior (CAPES).

A estratégia seguinte consistiu em adentrar no sistema "qualis capes", área de agrárias. Para cada classificação, foram selecionados visualmente os periódicos que publicam predominantemente pesquisas na área de Engenharia Florestal e, após, refinou-se a pesquisa utilizando o termo "arborização urbana", "Nordeste do Brasil”, para a década de 2008 a 2017. Os artigos encontrados foram salvos em arquivo digital, para posterior análise.

A terceira etapa consistiu em catalogar as seguintes informações:

a) observar o título do periódico, o sistema de classificação e a quantidade de artigos encontrados;

b) relacionar a instituição que desenvolveu a pesquisa e os pesquisadores;

c) verificar as metodologias predominantes empregadas nos artigos, transcrevendo os termos que descrevem a metodologia, classificadas em: - Inventário, censo ou diagnóstico de arborização do ambiente selecionado para a pesquisa, abrange, identificação das espécies arbóreas, dendrometria, levantamento das condições fitossanitárias, localização da árvore, situação do meio (RODOLFO JÚNIOR et al., 2008);

- Sensoriamento Remoto, uso de tecnologia para obtenção das informações, utilizando um sensor que captura as informações ã distância, sem haver contato com o alvo, mais utilizado para grandes áreas, em que os métodos localizados ficam muito custosos, este método auxilia para identificar manchas arbóreas e não condições mais específicas sobre a planta (FEITOSA et al., 2011);

- A utilização de percepção abrange a tomada de consciência pelo ser humano das condições ambientais, mensura a resposta psicológica dos usuários dos espaços pesquisados (LACERDA et al., 2010).

d) identificar a região onde os trabalhos foram desenvolvidos.

Os dados coletados foram tabulados, sendo aplicada a estatística descritiva e análise e discussão dos mesmos. 


\section{RESULTADOS E DISCUSSÃO}

Os resultados deste levantamento estão apresentados na seguinte ordem: o inventário dos periódicos nacionais que publicam sobre arborização urbana no Nordeste e respectivos artigos; Identificação dos autores, instituições, áreas, metodologias predominantes nas áreas pesquisadas, as conclusões sobre o estado da arte das respectivas pesquisas, a partir de um resumo conjunto das publicações.

\section{Periódicos nacionais que publicam sobre arborização urbana no Nordeste e respectivos artigos}

A partir do emprego da metodologia, pôde-se identificar, para o período de 2008 e 2017, 23 publicações sobre arborização urbana no Nordeste do Brasil em oito periódicos, sendo estes a Revista da Sociedade Brasileira de Arborização Urbana (REVSBAU) (ISSN 1980-7694), Agropecuária Científica no Semiárido (ACSA) (ISSN 1808 6845), Casa da Geografia de Sobral (ISSN 2316 8056), Principia (ISSN 1517-0306), Revista Verde de Agroecologia, Desenvolvimento Sustentável (ISSN 1981-8203), Revista Árvore (ISSN 1806-9088), Ciência Florestal (ISSN 1980-5098) e Enciclopédia Biosfera (ISSN 2317-2606). Considerando os artigos publicados, a REVSBAU concentrou $54,2 \%$ das publicações e a ACSA outros $16,7 \%$, e os demais periódicos apresentaram uma publicação cada, correspondendo a 4,35\%.

Com exceção da Revista Verde de Agroecologia e a Enciclopédia Biosfera, todos os outros periódicos se vinculam à Instituições de ensino superior, metade delas são de instituições da região Nordeste e a outra metade nas regiões Sul e Sudeste. Todos os periódicos têm indexadores, armazenadores e divulgadores das publicações científicas. A revista Ciência Florestal foi a que apresentou o maior número de indexadores, com 31 ao todo.

\section{Identificação dos trabalhos publicados pelos periódicos, respectivos estados, instituições, metodologias utilizadas}

As tabelas 1, 2 e 3 relacionam os artigos identificados por periódico. A Tabela 1 apresenta o perfil das publicações na REVSBAU, esta se sobressai pela quantidade de artigos vinculados à região Nordeste.

Dos 13 artigos identificados publicados na REVSBAU, pesquisadores da Universidade Federal de Campina Grande (UFCG) publicaram cinco artigos, os da Universidade Federal de Sergipe (UFS), Universidade Federal do Rio Grande do Norte (UFRN) e da Universidade do Vale do Acaraú (UVA), dois artigos cada uma e, os da Universidade Federal do Piauí (UFPI) e do Instituto Federal do Ceará (IFCE), com apenas um artigo cada. Identificou-se a preponderância das pesquisas realizadas pelos pesquisadores da UFCG e que, 54\% destas foram desenvolvidas no semiárido nordestino. Destaca-se, neste periódico, uma publicação com a "Indicação de 
Espécies de Porte para a Arborização Urbana no Semiárido Paraibano", pesquisa importante pela sua característica norteadora das atividades de arborização urbana, notadamente na região de grande insolação que é o semiárido brasileiro e que pode servir de norteamento para aplicação no bioma.

Tabela 1. Publicações sobre arborização urbana no Nordeste encontradas na Revista Brasileira de Arborização Urbana, para o período de 2008 a 2017

Table 1. Publications on urban afforestation in the northeast region found in the Revista Brasileira de Arborização Urbana, for the period from 2008 to 2017

\begin{tabular}{|c|c|c|c|c|}
\hline Ano & $\begin{array}{l}\text { Instituição } \\
\text { resp. }\end{array}$ & Títulos & Método & Local \\
\hline $\begin{array}{l}\text { T01 / } \\
2008\end{array}$ & UFCG & $\begin{array}{l}\text { Análise da Arborização } \\
\text { Urbana em Bairros da cidade } \\
\text { de Pombal no Estado da } \\
\text { Paraíba }\end{array}$ & $\begin{array}{l}\text { Inventário total em quatro } \\
\text { ruas de cada bairro, uso } \\
\text { de formulário }\end{array}$ & Pombal/PB \\
\hline $\begin{array}{l}\text { T02/ } \\
2009\end{array}$ & UFCG & $\begin{array}{l}\text { Análise Quantitativa da } \\
\text { Arborização Urbana de } \\
\text { Lavras da Mangabeira, CE, } \\
\text { Nordeste do Brasil }\end{array}$ & Inventário & $\begin{array}{l}\text { Lavras da } \\
\text { Mangabeira/CE }\end{array}$ \\
\hline $\begin{array}{l}\text { T03 / } \\
2009\end{array}$ & UFCG & $\begin{array}{l}\text { Experiência Piloto em } \\
\text { Arborização Participativa em } \\
\text { duas cidades de pequeno } \\
\text { porte do Semi }- \text { Árido } \\
\text { Brasileiro }\end{array}$ & $\begin{array}{l}\text { Inventário e execução de } \\
\text { plano de arborização. }\end{array}$ & $\begin{array}{l}\text { São Mamede e } \\
\text { São José do } \\
\text { Bonfim/PB }\end{array}$ \\
\hline $\begin{array}{l}\text { T04 / } \\
2009\end{array}$ & UFS & $\begin{array}{l}\text { Composição Florística de } 25 \\
\text { Vias Públicas de Aracaju - } \\
\text { SE }\end{array}$ & Inventário. & Aracaju/SE \\
\hline $\begin{array}{l}\text { T05 / } \\
2009\end{array}$ & $\begin{array}{l}\text { UFRN } \\
\text { UNIFIP* }\end{array}$ & $\begin{array}{l}\text { Análise Quali - Quantitativa } \\
\text { da Arborização no Bairro } \\
\text { Presidente Médici, Campina } \\
\text { Grande; }\end{array}$ & Inventário & $\begin{array}{l}\text { Campina } \\
\text { Grande/PB }\end{array}$ \\
\hline $\begin{array}{l}\text { T06 / } \\
2010\end{array}$ & UFCG & $\begin{array}{l}\text { Percepção dos residentes } \\
\text { sobre a arborização da } \\
\text { cidade de São José de } \\
\text { Piranhas-PB }\end{array}$ & Entrevista & $\begin{array}{l}\text { São José de } \\
\text { Piranhas/PB }\end{array}$ \\
\hline $\begin{array}{l}\text { T07 } \\
2011\end{array}$ & UFCG & $\begin{array}{l}\text { Indicação de } \\
\text { Porte para a } \\
\text { Urbéies de } \\
\text { Urbana no } \\
\text { Paraibano }\end{array}$ & $\begin{array}{l}\text { Inventário; análise das } \\
\text { potencialidades } \\
\text { paisagísticas; Indicação } \\
\text { das espécies para a } \\
\text { arborização urbana. }\end{array}$ & $\begin{array}{l}\text { Território do } \\
\text { Médio Sertão } \\
\text { Paraibano }\end{array}$ \\
\hline $\begin{array}{l}\text { T08 } \\
2011\end{array}$ & UFS & $\begin{array}{l}\text { Índices de Densidade e } \\
\text { Sombreamento Arbóreo em } \\
\text { Árvores em Áreas Verdes } \\
\text { Públicas de Aracaju, Sergipe }\end{array}$ & Inventário & Aracaju/SE \\
\hline $\begin{array}{l}\text { T09 } \\
2011\end{array}$ & UFPI & $\begin{array}{l}\text { Inventário da Arborização do } \\
\text { Parque da Cidade do } \\
\text { Município de Sobral, Ceará }\end{array}$ & $\begin{array}{l}\text { Sensoriamento remoto; } \\
\text { (Landsat-5); Índice de } \\
\text { áreas verdes (1989- } \\
\text { 2009). }\end{array}$ & Teresina/PI \\
\hline
\end{tabular}

continua... 
...continuação

\begin{tabular}{|c|c|c|c|c|}
\hline Ano & $\begin{array}{l}\text { Instituição } \\
\text { resp. }\end{array}$ & Título & Método & Local \\
\hline $\begin{array}{l}\text { T10 } \\
2012\end{array}$ & UVA & $\begin{array}{l}\text { Consequências da } \\
\text { Urbanização na Vegetação e } \\
\text { na Temperatura da Superfície } \\
\text { de Teresina - Piauí }\end{array}$ & Inventário. & Sobral/CE \\
\hline $\begin{array}{l}\text { T11 } \\
2012\end{array}$ & $\begin{array}{l}\text { IBAMA } * \text { CE } \\
\text { IFCE }\end{array}$ & $\begin{array}{l}\text { Avaliação da Qualidade } \\
\text { Ambiental da Arborização de } \\
\text { Ruas de Bairros Aldeota e } \\
\text { Messejeana, Fortaleza / CE }\end{array}$ & Inventário & Fortaleza/CE \\
\hline $\begin{array}{l}\text { T12 } \\
2012\end{array}$ & UFRN & $\begin{array}{l}\text { Análise da Arborização Viária } \\
\text { do Bairro de Petrópolis, Natal, } \\
\text { RN: uma abordagem para } \\
\text { diagnóstico e Planejamento da } \\
\text { Flora Urbana }\end{array}$ & Inventário & Natal/RN \\
\hline $\begin{array}{l}\text { T13 } \\
2013\end{array}$ & UVA & $\begin{array}{l}\text { Levantamento Quali - } \\
\text { Quantitativo da Arborização } \\
\text { Urbana do Distrito de Rafael } \\
\text { Arruda, Sobral, CE }\end{array}$ & Inventário & $\begin{array}{l}\text { Distrito de } \\
\text { Rafael Arruda/ } \\
\text { Sobral/CE }\end{array}$ \\
\hline
\end{tabular}

* Instituto Brasileiro de Meio Ambiente

A tabela 2, apresenta os quatro artigos publicados pela Agropecuária Científica no Semiárido (ACSA), no período de 2014 a 2017, todos produzidos pela UFCG. Dois deles foi desenvolvido em praças, um sobre percepção da arborização urbana, sendo três deles desenvolvidos no bioma caatinga. Considerando os estados federativos, três deles foram produzidos no estado da Paraíba e um no Rio Grande do Norte.

Tabela 2. Publicações sobre arborização urbana no Nordeste encontradas na Agropecuária Científica no Semiárido, para o período de 2014 a 2017

Table 2. Publications on urban afforestation in the northeast region found in the Agropecuária Científica no Semiárido, for the period from 2008 to 2017

\begin{tabular}{clllc}
\hline Ano & $\begin{array}{l}\text { Instituição } \\
\text { responsável }\end{array}$ & Pesquisadores(as) & Método & Local \\
\hline T14 / & UFCG & $\begin{array}{l}\text { Levantamento e diversidade da } \\
\text { arborização urbana de Santa Helena, } \\
\text { no semiárido da Paraíba }\end{array}$ & Inventário & $\begin{array}{c}\text { Santa } \\
\text { Helena/PB }\end{array}$ \\
T15 / & UFCG & $\begin{array}{l}\text { Inventário Quali - Quantitativo da } \\
\text { Arborização Urbana em São João do } \\
\text { Rio do Peixe - PB }\end{array}$ & Inventário & $\begin{array}{c}\text { São João do } \\
\text { Rio do } \\
\text { Peixe/PB }\end{array}$ \\
T16 / & UFCG & $\begin{array}{l}\text { Análise Quali - Quantitativa da } \\
\text { arborização da Praça Pedro Velho, } \\
\text { Natal, RN }\end{array}$ & Inventário & Natal/RN \\
T17 / & UFCG & $\begin{array}{l}\text { Percepção da população relacionada à } \\
\text { arborização urbana de praças no centro } \\
\text { da cidade de Patos-PB }\end{array}$ & Entrevista & Patos/PB \\
2016 & & & \\
\hline
\end{tabular}

A tabela 3, sintetiza as publicações dos seis periódicos restantes, com apenas uma publicação em cada um deles. Considerando os estados pesquisados, verificou-se que o Ceará, Paraíba e Sergipe registraram duas pesquisas em cada e no Piauí, apenas uma. 
Observa-se que em $71 \%$ dos artigos, a pesquisa foi desenvolvida nas ruas, um dos trabalhos utilizou a ferramenta de geoprocessamento para localização de indivíduos arbóreos e outro, uma experiência sobre a participação popular no processo de arborização. As pesquisas do Departamento de Ciências Florestais da Universidade Federal de Sergipe, preponderou neste grupo com $28,6 \%$ das publicações.

Tabela 3. Publicações sobre arborização urbana no Nordeste encontradas em seis periódicos das agrárias, no período de 2008 a 2017

Table 3. Publications on urban afforestation in the northeast region in six agrarian journals, for the period from 2008 to 2017

\begin{tabular}{|c|c|c|c|c|}
\hline \multirow[t]{2}{*}{ Ano } & $\begin{array}{l}\text { Instituição } \\
\text { responsável }\end{array}$ & Pesquisadores(as) & Método & Local \\
\hline & \multicolumn{4}{|c|}{ Casa da Geografia de Sobral } \\
\hline \multirow[t]{2}{*}{$\begin{array}{l}\text { T18 / } \\
2016\end{array}$} & UVA & $\begin{array}{l}\text { Inventário da Arborização de um Bairro } \\
\text { da cidade de Parnaíba - Piauí, com } \\
\text { utilização de um Sistema de Informação } \\
\text { Geográfico. }\end{array}$ & Inventário & $\begin{array}{l}\text { Parnaíba/ } \\
\text { PI }\end{array}$ \\
\hline & \multicolumn{4}{|c|}{ PRINCIPIA } \\
\hline \multirow[t]{2}{*}{$\begin{array}{l}\text { T19/ } \\
2017\end{array}$} & IFPB & $\begin{array}{l}\text { Levantamento Quali - Quantitativo da } \\
\text { Arborização Urbana da cidade de Baixio - } \\
\text { CE. }\end{array}$ & Inventário & $\begin{array}{l}\text { Baixio/ } \\
\text { CE }\end{array}$ \\
\hline & \multicolumn{4}{|c|}{ Revista Verde de Agroecologia e Desenvolvimento Sustentável } \\
\hline \multirow[t]{2}{*}{$\begin{array}{l}\text { T20 / } \\
2015\end{array}$} & UFCG & $\begin{array}{l}\text { Arborização em canteiros centrais na } \\
\text { cidade de Patos, Paraíba. }\end{array}$ & Inventário & Patos/PB \\
\hline & \multicolumn{4}{|c|}{ Revista Árvore } \\
\hline \multirow[t]{2}{*}{$\begin{array}{l}\text { T21/ } \\
2011\end{array}$} & UFS & $\begin{array}{l}\text { Diagnóstico Quantitativo e Qualitativo da } \\
\text { Arborização das Praças de Aracaju, SE }\end{array}$ & Inventário & Aracaju/SE \\
\hline & \multicolumn{4}{|c|}{ Ciência Florestal } \\
\hline \multirow[t]{2}{*}{$\begin{array}{l}\text { T22 / } \\
2015\end{array}$} & UFS & $\begin{array}{l}\text { Análise Quantitativa da Arborização } \\
\text { Urbana de } 25 \text { Vias Públicas da cidade de } \\
\text { Aracaju-SE }\end{array}$ & Inventário & Aracaju/SE \\
\hline & \multicolumn{4}{|c|}{ Enciclopédia Biosfera } \\
\hline $\begin{array}{l}\text { T23 / } \\
2013\end{array}$ & $\begin{array}{l}\text { Centro } \\
\text { Científico } \\
\text { Conhecer }\end{array}$ & $\begin{array}{l}\text { Análise quanti-qualitativa das espécies } \\
\text { arbóreas presentes no parque religioso } \\
\text { Cruz da Menina, Patos/PB. }\end{array}$ & Inventário & Patos/PB \\
\hline
\end{tabular}

Avaliando as 23 publicações, identificou-se que $46 \%$ dos artigos publicados foram produzidos pelo curso de Engenharia Florestal da UFCG, a maioria, no Estado da Paraíba. Verificou-se que esta instituição desenvolve pesquisas que incluem os estados do Ceará e Rio Grande do Norte.

O Curso de Engenharia Florestal, localizado em Patos, no estado da Paraíba, foi criado com a missão de contribuir com a compreensão das características do bioma caatinga, embora com foco na flora, também contribui com as áreas correlatas, envolvendo recursos naturais e humanidades, neste sentido se reconhece a contribuição que oferece a este campo de pesquisa e de inventário.

As publicações que foram desenvolvidas, no Piauí e Sergipe ficaram sob a responsabilidade de instituições de ensino e apenas uma foi produzida por equipe do IBAMA, 
em parceria com a UFC. A metodologia predominante foi inventário ou censo, com uso de formulário para identificar as condições fitossanitárias, estado de conservação do local, emprego de levantamento florístico ou identificação das espécies pela observação e experiência dos pesquisadores e $77 \%$ dos artigos foram desenvolvidos em ruas e avenidas.

\section{Estados citados nas publicações}

Os trabalhos analisados foram desenvolvidos em 5 estados da região nordeste, não ocorrendo nenhuma publicação para na Bahia, Alagoas, Pernambuco e Maranhão. A Paraíba se destacou, com $43 \%$ das publicações, todas desenvolvidas no interior do estado. Neste caso, se reconhece a importância das pesquisas realizadas pela UFCG no semiárido, pois nenhum deles ocorreu em região de mata atlântica. As pesquisas no estado do Ceará, envolveu a capital Fortaleza e o restante no interior. No estado de Sergipe, todas três foram realizadas na capital Aracajú. Os estados do Rio Grande do Norte e Piauí, tiveram duas publicações cada um, sendo uma na capital e outra em cidade do interior.

Em relação ao período de publicação, o estado da Paraíba totalizou dez publicações distribuídas, ao longo dos dez anos, exceto nos anos de 2012 e 2013, e destaque para o município de Patos, com três publicações (T17, T20 e T23), em 2014, 2015 e 2017, vinculados à UFCG.

O Ceará, com publicações em 2009, 2012, 2013 e 2017, seguido de Aracajú com quatro trabalhos, nos anos de 2009, 2011 e 2015. O Rio Grande do Norte, com publicações nos anos de 2012 e 2016 e finalmente o Piauí, com publicações nos anos de 2011 e 2016.

Identifica-se poucas pesquisas desenvolvidas neste tema e, notadamente, de forma muito limitada a identificação da percepção sobre arborização urbana, o que serve de base para as atividades de educação ambiental, que é fundamental para a mudança de postura da população.

As pesquisas precisam abranger mais informações sobre o estado da arborização nos municípios, para contribuir para a sustentabilidade ambiental nas áreas urbanas. Quanto às capitais nordestinas, que abrangem região de mata atlântica, reconhecidamente degradada, estas pesquisas irão apontar os principais problemas enfrentados. Quanto à região semiárida as informações apresentadas nas pesquisas auxiliam a compreender que, em geral, as praças e avenidas são arborizadas sem atender a um planejamento paisagístico.

Embora a contribuição da UFCG, especificamente a Engenharia Florestal, seja relevante, há um hiato entre as pesquisas publicadas e as ações por parte das administrações municipais. Destaca-se a relevância da educação ambiental como medida sensibilizadora da importância da flora para o equilíbrio ambiental e térmico. 


\section{Publicações por Instituição sobre arborização urbana no Nordeste, entre 2008 a 2017}

Neste levantamento, foram citadas 7 instituições no período de 2008 a 2017. A UFCG foi a que mais se destacou, com 10 publicações, seguida pela Universidade Federal de Sergipe (UFS) com e a Universidade do Vale do Acaraú (UVA) com 4 e 3 publicações, respectivamente. Ao identificar as instituições de ensino e pesquisa que publicaram, se favorece a troca de informações ao identificar onde estão situadas as pesquisas, norteando o contato com equipes de trabalho.

\section{Estado da arte das respectivas pesquisas}

Apresenta-se um resumo dos trabalhos publicados, organizados por município e, estes por bioma. Foram organizadas as pesquisas desenvolvidas no semiárido; na mata atlântica, de clima tropical e um trabalho apresentado em separado que foi desenvolvido em região de transição climática, na serra da Borborema, entre o clima tropical e o semiárido, no estado da Paraíba. Com esta organização pretende-se dar uma visão sinótica das produções identificadas, incluindo as conclusões das mesmas.

Foram onze trabalhos desenvolvidos no semiárido com inventário de espécies, um sobre arborização participativa e outro que são indicações de espécies para o semiárido. Rodolfo Júnior; Melo e Cunha (2008), realizaram o inventário em três bairros da cidade de Pombal (PB), utilizaram a metodologia de inventário e identificaram que há predominâncias da espécie Ficus benjamina (Figo) (51\%) e que a arborização foi realizada sem um prévio planejamento técnico. Crispim et al. (2014), realizaram o levantamento quantitativo da arborização urbana no centro da cidade de Pombal, foram inventariados 1441 árvores, com predomínio da Azadirachta indica A. Juss (Nin indiano), perfazendo $42 \%$ do total, verificaram também danos à estrutura física das calçadas, trechos com ausência de árvores, problemas de fitossanidade e podas mal conduzidas. Estes dois trabalhos foram realizados no mesmo município e pode-se verificar que num intervalo de seis anos houve diferença entre a espécie predominante, ambas são exóticas. Pode ter ocorrido neste intervalo de seis anos a substituição das árvores, inclusive, porque o fícus traz problemas para os encanamentos, entupimento, e rachaduras nas calçadas.

Calixto Júnior, Santana e Lira Filho (2009) realizaram inventário total no município de Lavras da Mangabeira/CE, incluindo coleta de material botânico. Identificaram, predominância do Ficus benjamina (41\%) e a necessidade de reordenação do planejamento paisagístico. VALE et al. (2011) realizaram a pesquisa no Parque da Cidade, no município de Sobral/CE, realizaram inventário e coleta de material botânico, concluindo pela predominância das espécies nativas, com baixa diversidade florística. Sousa; Figueiredo e Braga (2013), estudaram 17 ruas do distrito de Rafael Arruda, em Sobral/CE, utilizando inventário e levantamento florístico, identificaram a predominância de Azadirachta indica, com 52\% das ocorrências, verificando baixa diversidade 
florística, alta frequência de indivíduos exóticos e concluindo pela ausência de planejamento da arborização no distrito.

Zea et al. (2015), desenvolveram sua pesquisa no município de Santa Helena/PB, utilizando inventário com auxílio de formulário e concluíram que há o predomínio de espécies exóticas, em 95,5\% dos casos, com predomínio do Azadirachta indica, a pesquisa indicou baixa diversidade florística, que gera risco maior de problemas fitossanitários e os problemas ecológicos que este perfil apresenta.

Alencar et al. (2011) realizaram a avaliação quantitativa e qualitativa dos indivíduos arbóreos no Município de São João do Rio do Peixe/PB, para o reconhecimento das espécies fez-se a comparação com o material do Herbário Rita Baltazar do CSTR/UFCG, identificaram que 53\% dos indivíduos são da espécie Azadirachta indica, os indivíduos que predominam são de porte baixo, pelas características dos plantios, verifica-se a ausência de orientação técnica, de forma que os moradores plantam as mudas sem atentar para a interferência na rede elétrica, no espaço para o desenvolvimento da parte radicular e aérea da planta, os indivíduos apresentavam boa fitossanidade e a maioria das espécies é exótica.

Crispim et al. (2017) realizaram a análise quali-quantitativa de 2008 indivíduos em São João do Rio do Peixe/PB, com 137 deles em fase juvenil, identificaram predomínio de exóticas (96,7\%), sendo 53\% de Azadirachta indica, demonstrando a falta de orientação técnica na escolha das espécies e destacam que a população escolhe seu próprio plantio.

Foram encontrados três trabalhos referentes ao município de Patos/PB. Nóbrega et al (2014) pesquisaram o Parque Religioso Cruz da Menina e encontraram 158 indivíduos arbóreos, com predominância de Prosopolis juliflora (Sw) DC (Algaroba), sugeriram aumentar a área de cobertura vegetal, que é de $30 \%$, e os indivíduos existentes estão em bom estado de conservação. A outra pesquisa foi realizada por Lucena et al. (2015) desenvolvido nos canteiros centrais de Patos/PB, identificaram a predominância de Azadirachta indica (42\%), identificaram muitos conflitos com o meio urbano e problemas de podas mal conduzidas. Os pesquisadores consideram que Patos/PB enfrenta um "modismo" na adoção da espécie conhecida por "Nin indiano", que tem desenvolvimento rápido e copa bem fechada, ideal para sombreamento. $O$ terceiro artigo de Souza et al. (2016) envolveu a percepção dos usuários das praças Edvaldo Motta, Getúlio Vargas e Alcides Carneiro, situadas no centro da cidade. A pesquisa concluiu que os usuários consideram a arborização das praças insuficiente e que o maior benefício que as árvores proporcionam é a sombra.

Destaca-se os trabalhos de Lacerda et al. (2011) que trabalharam com a indicação de espécies arbóreas para Arborização Urbana no Semiárido Paraibano e o trabalho dos pesquisadores Lira Filho et al. (2009) que trouxe uma "Experiência Piloto em Arborização 
Participativa em duas cidades de Pequeno Porte no Semiárido Brasileiro", ambas publicadas pela Revista Brasileira em Arborização Urbana.

O ultimo trabalho, na Paraíba, em área de transição climática, Araújo et al (2009) em inventário no bairro Presidente Médici, Campina Grande/PB, identificaram a predominância do Ficus benjamina (52\%), baixa diversidade florística, podas emergenciais mal executadas ou ausentes, inadequação entre o porte da árvore e o tamanho da área livre.

Carvalho, Nogueira e Lemos (2016) realizaram um inventário da Arborização do bairro nova Parnaíba/Terezina/PI, reconhecido por ser bem arborizado em relação aos demais bairros da cidade, utilizaram também a ferramenta auxiliar de georeferenciamento para mapeamento das árvores no bairro, para a identificação das espécies foi utilizada literatura especializada. Eles concluíram que $86 \%$ das espécies são exóticas, as calçadas encontram-se, em sua maioria, sem danos, mas destacaram a necessidade de planejamento urbano para alcançar diversidade florística e, neste, inclusive integrar os diversos usuários do perímetro urbano, tais como concessionárias de energia, telefonia e os governos.

Feitosa et al. (2011), estudaram as consequências da Urbanização na Vegetação e na Temperatura da Superfície de Teresina/PI, que é considerada uma área de transição entre o bioma caatinga e a mata amazônica. Este trabalho utilizou a ferramenta de geoprocessamento e a análise de imagens do satélite LANDSAT-5 para verificar a relação decrescente da vegetação com o aumento na urbanização e a consequente interferência no microclima local.

$\mathrm{Na}$ área litorânea do Nordeste encontrou-se sete trabalhos, desenvolvidos nas capitais de Fortaleza/CE, Natal/RN, e Aracajú/SE. Freire, Silva e Tavares Júnior (2012) estudaram ruas dos bairros Aldeota e Messejanea, em Fortaleza/CE, os bairros foram selecionados pela diferença socioeconômica dos seus moradores e as avenidas selecionadas intencionalmente. Houve predominância do Ficus sp. em ambos bairros, os autores questionam esta escolha, tendo em vista que o sistema radicular desta espécie é bastante agressivo e danifica calçadas, além de adentrar em encanamentos, incluindo incompatibilidade entre a espécie plantada e o espaço na calçada; conflitos com a rede elétrica e registraram que cerca de $80 \%$ das plantas se encontram com problemas fitossanitários, tendo como uma das causas podas mal realizadas.

Costa (2014) trabalhou com percepção e estudou sobre o interesse da participação popular no processo de arborização urbana, identificando que os entrevistados têm interesse em participar do processo, entretanto verificaram que falta conhecimento técnico para fazer a escolha da espécie de acordo com as condições do ambiente disponível e que o poder público poderia suprir esta aus6encia e envolver a população em ações de arborização das vias públicas.

As três pesquisas realizadas em Aracajú, envolveram apenas dois grupos de pesquisadores. Lima Neto, Melo e Sousa (2011) trabalharam com densidade e sombreamento arbóreo em áreas verdes em Aracajú; enquanto Santos et al. (2011) estudaram a composição 
florística de 25 vias públicas de Aracajú, concluindo pelo padrão de muitos indivíduos e poucas espécies, com predomínio de exóticas e Sousa et al. (2011) trabalhou com 22 praças públicas também com a composição florística, com $58 \%$ de espécies exóticas.

O levantamento realizado no Bairro de Petrópolis, em Natal/RN (SANTOS, LISBOA e CARVALHO, 2012), identificou predominância da espécie Syzygium malaccense (Jambo). Este trabalho é rico em sugestões para um plano municipal de arborização e, destaca a necessidade educação ambiental, para, inclusive, deter os atos de vandalismo praticados contra as árvores.

Araújo et al. (2015), realizaram o inventário de 85 indivíduos na praça Pedro Velho, Natal/RN e encontraram que o percentual de cobertura da praça é de $35 \%$. Concluíram que os resultados mostraram um equilíbrio na presença de espécies exóticas e nativas, com boa qualidade da copa e do tronco, resultando em alta qualidade ambiental.

\section{CONCLUSÕES}

Diante do levantamento realizado pode-se concluir que foram encontrados oito periódicos com publicações sobre arborização urbana no Nordeste, no período de 2008 a 2017, totalizando 23 artigos, sendo treze desenvolvidos no semiárido, três em área de transição climática e sete em clima tropical (litoral). O estado que mais apresentou trabalhos foi a Paraíba e a instituição foi a Universidade Federal de Campina Grande.

A metodologia predominante no levantamento foi o inventário, com identificação qualiquantitativa, em ruas ou praças; uso do sensoriamento remoto. Dois trabalhos se diferenciaram do conjunto por realizar um planejamento participativo da arborização urbana e outro trabalho que indicou espécies para avenidas, praças e áreas ciliares no semiárido brasileiro.

A maioria dos trabalhos desenvolvidos concluíram pela predominância de espécies exóticas. As espécies com maior ocorrência são Azadirachta indica A. Juss (Nin indiano), seguido da Ficus benjamina L. (Ficus). No semiárido apenas um trabalho concluiu que há predominância de plantas nativas, o Parque da Cidade, em Sobral/CE. Nos trabalhos da zona de transição climática e do litoral, as conclusões são semelhantes, indicando o predomínio de exóticas. Nos trabalhos do litoral, verifica-se a predominância de árvores frutíferas, como Syzygium malaccense L Merr. \& L. M. Perry (Jambo) e Mangueira indica L (manga). Todos os trabalhos sugerem a necessidade de planejamento da arborização urbana e dois deles sugerem a realização de atividades de educação ambiental com a população.

Há necessidade de mais pesquisas nesta área para o Nordeste brasileiro, inclusive destacando todas as vantagens da arborização e que um planejamento paisagístico respeite o bioma local, evitando os problemas identificados nos trabalhos publicados. 


\section{REFERÊNCIAS}

ALENCAR, L. dos S. ALENCAR; SOUTO, P. C. ; MOREIRA, F. T. de A. SOUTO, J. S.; BORGES, C. H. A. Inventário Quali - Quantitativo da Arborização Urbana em São João do Rio do Peixe PB. Agropecuária Científica no Semiárido (ACSA), Patos, v. 10, n. 2, p. 117-124, 2011.

ARAúJO, A. C. de; RIBEIRO, A. M. MORAIS, M. dos S.; ARAÚJO, J. de L. O. Análise Quali Quantitativa da Arborização no Bairro Presidente Médici, Campina Grande; Revista da Sociedade Brasileira de Arborização Urbana, Piracicaba, v. 4, n. 1, p. 133 - 144, 2009.

ARAúJO, L. H. B. de.; NÓBREGA, C. C. da; SALES, A. C. F. VIEIRA, F. de A. Análise Quali Quantitativa da arborização da Praça Pedro Velho, Natal, RN. Agropecuária Científica no Semiárido (ACSA), Patos, v. 11, n. 1, p. 65-71, 2015.

CALIXTO JÚNIOR, J. T; SANTANA, G. M. de; LIRA FILHO, J. A. Análise Quantitativa da Arborização Urbana de Lavras da Mangabeira, CE, Nordeste do Brasil. Revista da Sociedade Brasileira de Arborização Urbana, Piracicaba, v. 4, n. 3, p. 99 - 109, 2009.

CARVALHO, L. A. de; NOGUEIRA, J. F. LEMOS, J. R. Inventário da Arborização de um Bairro da cidade de Parnaíba - Piauí, com utilização de um Sistema de Informação Geográfico. Revista da Casa de Geografia de Sobral, Sobral, v. 18, n. 1, p. 100 - 117, 2016.

COSTA, C. G. F. Avaliação preliminar da participação popular no processo de Arborização Urbana na cidade de Fortaleza (CE). PRACS: Revista Eletrônica de Humanidades do Curso de Ciências Sociais da UNIFAP, Macapá, v. 7, n. 2, p. 35-50, 2014.

CRIPIM, D. L. ARAUJO, L. M. CRUZ, J. da S.; SILVA, J. I. S. Levantamento Quali - Quantitativo da Arborização Urbana da cidade de Baixio - CE. PRINCIPIA, João Pessoa, PB. Divulgação científica e tecnológica do IFPB, n. 36, 2017. Disponível em:< http://periodicos.ifpb.edu.br/index.php/principia/article/view/972>, acesso em: 03 nov 2019.

CRISPIM, D. L.; SILVA, M. A. da; CHAVES, A. D. C. ; ALMEIDA, R. R. P. de; FREITAS, A. J. F. de. Diagnóstico da Arborização Urbana do centro da cidade de Pombal - PB. Revista Verde de Agroecologia e Desenvolvimento Sustentável, Mossoró, v. 9, n. 1, p. 191-196, 2014.

FEITOSA, S. M. R.; GOMES, J. M. A. MOTA NETO, J. M.; ANDRADE, D. S. P. de A. Consequências da Urbanização na Vegetação e na Temperatura da Superfície de Teresina Piauí. REVSBAU, Piracicaba, v. 6, n. 2, p. 58 - 75, 2011.

FREIRE, R. L. da S.; SILVA, A. C. da; TAVARES JÚNIOR, J. M. Avaliação da Qualidade Ambiental da Arborização de Ruas de Bairros Aldeota e Messejena, Fortaleza / CE. Revista da Sociedade Brasileira de Arborização Urbana, Piracicaba, v. 7, n. 2, p. 116 - 127, 2012.

HERCULANO, S. C. Do Desenvolvimento (in)suportável à Sociedade Feliz. In: GOLDENBERG, M. (org). Ecologia, Ciência e Política. Rio de Janeiro: Revan, 1992.

LACERDA, R. M. de A.; LIRA FILHO, J. A.; SANTOS, R. V. dos. Indicação de Espécies de Porte para a Arborização Urbana no Semiárido Paraibano. Revista da Sociedade Brasileira de Arborização Urbana, Piracicaba, v. 6, n. 1, p. 51 - 68, 2011.

LIMA NETO, E. M. de; MELO E SOUSA, R. Índices de Densidade e Sombreamento Arbóreo em Árvores em Áreas Verdes Públicas de Aracaju, Sergipe. Revista da Sociedade Brasileira de Arborização Urbana, Piracicaba, v. 4, n. 4, p. 47 - 62, 2009. 
LIRA FILHO, J. A.; FONSECA, C. M. B. da.; ALVES, P. S. ; LACERDA, R. M. A. de; Experiência Piloto em Arborização Participativa em duas cidades de Pequeno Porte no Semiárido Brasileiro. Revista da Sociedade Brasileira de Arborização Urbana, Piracicaba, v. 1, n. 1, p. 1 - 15, 2009.

LUCENA, J. N. de L.; SOUTO, P. C.; CAMAÑO, J. D. Z.; SOUTO, J. S.; SOUTO, L. S. Arborização em canteiros centrais na cidade de Patos, Paraíba. Revista Verde de Agroecologia e Desenvolvimento Sustentável, Mossoró, v. 10, n. 4, p. 20-26, 2015

NÓBREGA, C. C. da.; .; SOUTO, P. C.; ARAÚJO, L. H. B. de; SILVA, A. C. F. da; PINTO, M. G. C. Análise quanti-qualitativa das espécies arbóreas presentes no parque religioso cruz da menina, Patos/PB. Enciclopédia Biosfera, Goiânia, v. 10, n. 18, p. 299-307, 2014

RODOLFO JÚNIOR, F; MELO, R. R. de; CUNHA, T. A. da; STANGERLIN, D. M. Análise da Arborização Urbana em Bairros da cidade de Pombal no Estado da Paraíba. Revista da Sociedade Brasileira de Arborização Urbana, Piracicaba, v. 3, n. 4, p 3-19, 2008.

SANTOS, C. Z. A. dos; FERREIRA, R. A.; SANTOS, L. R.; SANTOS, L. I. GRAÇA, D. A. S. da; GOMES, S. H.; PORTO NETO, W. de B. CORREIA, T. S. BOSCHESE, A. C. de B. Composição Florística de 25 Vias Públicas de Aracaju - SE. Revista da Sociedade Brasileira de Arborização Urbana, Piracicaba, v. 6, n. 2, p. 125 - 144, 2011.

SANTOS, T. O. B. dos; LISBOA, C. M. C. A.; CARVALHO, F. G. de; Análise da Arborização Viária do Bairro de Petrópolis, Natal, RN: uma abordagem para diagnóstico e planejamento da flora urbana. Revista da Sociedade Brasileira de Arborização Urbana, Piracicaba, v. 7, n. 4, p. $70-106,2012$.

SOUSA, L. M. de; FIGUEIREDO, M. F. BRAGA, P. E. T. Levantamento Quali - Quantitativo da Arborização Urbana do Distrito de Rafael Arruda, Sobral, CE. Revista da Sociedade Brasileira de Arborização Urbana, Piracicaba, v. 8, n. 3, p. 118 - 129, 2013.

SOUZA, A. L. de; FERREIRA, A. L de; MELLO, A. A. de; PLÁCIDO, D. da R.; SANTOS, C. Z. A. dos; GRAÇA, D. A. S.da; ALMEIDA JÚNIOR, P.P. de; BARRETTO, S. S. B.; DANTAS, J. D. de M. PAULA, J. W. A. de; SILVA, T. L. da; GOMES, L. P. S.; Diagnóstico Quantitativo e Qualitativo da Arborização das Praças de Aracaju, SE. REVISTA ÁRVORE. Viçosa, v. 35, n. 6, p. 12531263, 2011.

SOUZA, M. A. S. de; SOUTO, P. C.; FERNANDES, S. P. dos S.; NEVES, A. de A. N.; LIMA, F.; SOUTO, J. S. Percepção da população relacionada à arborização urbana de praças no centro da cidade de Patos-PB. Agropecuária Científica no Semiárido (ACSA), Patos, v. 12, n. 4, p. 368-375, 2016.

SPÓSITO, E. S. A vida nas cidades. 3 ed. São Paulo: Contexto, 2001. p. 90.

VALE, N. F. L.; SOUSA, G. dos S.; MATA, M. F.; BRAGA, P. E. T. Inventário da Arborização do Parque da Cidade do Município de Sobral, Ceará. Revista da Sociedade Brasileira de Arborização Urbana, Piracicaba, v. 6, n. 4, p. 145 - 157, 2011.

ZEA, J. D. C.; BARROS, R. F.; SOUTO, P. C. SOUTO, J. S. ; Levantamento e diversidade da arborização urbana de Santa Helena, no semiárido da Paraíba. Agropecuária Científica no Semiárido (ACSA), Patos, v. 11, n. 4, p. 54 - 62, 2015. 